\title{
Crime in Huntington's disease: a study of registered offences among patients, relatives, and controls
}

\author{
Per Jensen, Kirsten Fenger, Tom G Bolwig, Sven Asger Sørensen
}

\begin{abstract}
Objectives-Criminal behaviour has been described as a problem in Huntington's disease, but systematic studies including control groups have been missing. Based on information from Danish registries, rates and types of crime committed by patients with Huntington's disease, nonaffected relatives, and controls were studied.

Methods-99 males and 151 females with Huntington's disease were compared with 334 non-affected first degree relatives (134 men and 200 women) and to matched control groups as to frequencies and types of registered criminal convictions. Due to specific age criteria, the group of relatives comprised only about $9 \%$ carriers of the gene coding for Huntington's disease.

Results-In male patients, crime rates were significantly increased compared with first degree relatives $(R R=2.8)$ and controls $(R R=2.3)$. All types of crime occurred more often in male patients; more severe crimes (murder, rape, arson) were not reported. Rates of drunken driving were significantly increased compared with relatives $(R R=3.8)$ and controls $(R R=7.1)$. Crime rates were neither increased in female patients nor in male and female first degree relatives.
\end{abstract}

Kommunehospitalet, University Hospital, Copenhagen, Department of Psychiatry P Jensen

Institute of Medical Biochemistry and

Genetics, University of Copenhagen

K Fenger

S A Sørensen

Rigshospitalet, University State

Hospital, Copenhagen, Department of

Psychiatry, Denmark

T G Bolwig

Correspondance to: Dr SA Sørensen, Institute of Medical Biochemistry and Genetics, Panum Institute, Blegdamsvej 3, DK-2200

Copenhagen N, Denmark.

Received 3 February 1998 and in revised form

6 May 1998

Accepted 12 May 1998

Despite low prevalence rates, Huntington's disease has always been subject to interest due to the combination of the characteristic clinical picture, the heritability, and the considerable burden laid on the patients and involved families. The disease is transferred as an autosomal on average $50 \%$ of offspring, and with a median age at onset in the mid-40s. ${ }^{1}$ The responsible gene has been cloned in $1993 .{ }^{2}$ The cognitive and neurological symptoms of progressing dementia and motor disturbances are characteristic and may well be considered purely genetically determined, whereas the psychiatric and behavioural symptoms are more heterogenous, probably due to a mixed genetic and psychosocial aetiology. Offspring of patients, who know about their risk, live several years of their lives with the fear of developing the disease, a chronically stressful situation that might produce psychological reactions in both future patients and siblings who show up not to be gene carriers. Even if offspring are not fully informed about the disease and its implications, it is well established that life in families of patients with Huntington's disease is often stressful due to familial disruption and social impairment. ${ }^{34}$

When studying psychiatric and behavioural phenomena in Huntington's disease, comparison of patients and non-affected siblings makes it possible to differentiate between biological and environmental aetiology. Using such a design, we recently studied the prevalence of admissions to psychiatric hospitals in Huntington's disease families, and were able to conclude that more severe psychiatric illness was aetiologically related to the disease process and not to the psychological and social environment in the families. ${ }^{5}$ With a similar design, this study focuses on crime in patients and relatives.

Criminal behaviour has been considered a problem of special relevance in Huntington's disease. ${ }^{3}$ Investigators from different countries have described populations in which 5\%-18\% of the patients were convicted of various sorts of crime including cases of murder.$^{6-8}$ One of these studies ${ }^{6}$ compared patients with nonaffected siblings and found serious crimes only among patients. On the other hand, Folstein et al, using DSM-III criteria, diagnosed conduct disorder or antisocial personality disorder in $25 \%$ of 112 offspring of patients with Huntington's disease, and found these disorders primarily related to disturbance in the families. ${ }^{9}$

It is difficult to conclude from these reports, dominant trait with high penetrance, affecting

however, as systematic studies with control groups have not been made. It seems to be a general assumption that various sorts of crime including serious offences occur relatively often among patients with Huntington's disease, but it is still uncertain whether the criminality rates are significantly increased compared with the normal population and to non- 
affected offspring of patients. In the present study, we combined information from the Danish Central Criminal Register (CCR) with data from a nationwide register for Huntington's disease, and the aims were the following:

(1) To estimate types and frequencies of convictions among a group of patients with Huntington's disease;

(2) To compare these data with corresponding information from (a) non-affected first degree relatives of patients with Huntington's disease; (b) matched control groups;

(3) To evaluate the relative importance of the psychosocial environment and of the gene coding for Huntington's disease on the development of criminal behaviour in patients with Huntington's disease and their relatives.

\section{Methods}

The subjects were selected from the register for Huntington's disease at the Institute of Medical Biochemistry and Genetics, University of Copenhagen. ${ }^{10}$ The registration is nationwide and is supposed to comprise all cases in Denmark. Two study groups were selected by the following criteria:

(1) All subjects registered with a diagnosis of Huntington's disease. They should be alive or have died within 2 years from the time of the study, as criminality data are deleted from the CCR 2 years from a person's death. Two hundred and fifty patients, 99 men and 151 women, fullfilled these criteria, the mean age of the men being 55.6 (SD 11.9) years, in women 58.2 (SD 15.0) years.

(2) All subjects registered with a prior Mendelian risk of $50 \%$ for being a carrier of the gene coding for Huntington's disease, but having reached the age of at least 55 without being affected themselves. Also these subjects should be alive or have died within 2 years. These criteria were fullfilled by 334 subjects, 134 men and 200 women, the mean age of the men being 68.3 (SD 9.3) years and women 71.6 (SD 9.7) years.

Some registered subjects had undergone presymptomatic genetic testing. They were all younger than 55 and were not included. For ethical reasons, they were not studied as a separate group. The higher number of women among the patients and among the at risk subjects may be due to a higher degree of attention in women than in men towards disease symptoms, both in themselves and in their parents, resulting in an earlier report to the register.

The reason for excluding at risk subjects below 55 years of age, was to reduce the number of gene carriers in this subgroup. In non-affected subjects at $50 \%$ prior risk, the remaining risk at different ages can be estimated by life table analyses. ${ }^{11}$ From the age distribution in the studied at risk subjects, we estimated that only about $9 \%$ of these subjects possessed the gene coding for Huntington's disease. As a group, however, they had in principle been exposed to the same psychological and environmental stressors as the patients, as they had grown up in Huntington's disease families with a risk of developing the disease themselves. The groups of patients and at risk subjects therefore were characterised by shared environment and different genetic loading. It follows that criminal behaviour in the group of non-affected offspring could only to a very small extent be considered genetically determined (that is, mediated by the gene coding for Huntington's disease), whereas crime in the group of patients could be genetically as well as environmentally determined.

For each of the persons in the two groups, control subjects were randomly selected from the Danish Central Register of Citizens, in which all inhabitants of Denmark are given their unique identity number, indicating sex and date of birth. The control subjects were matched to the study subjects for sex, age (within one year), and eventual year of death (in which a difference of 2 years was permitted). It was checked that no control subject was registered in the Huntington's disease register, and the probability of including gene carriers in the control groups therefore was negligible.

All study and control subjects were screened through the CCR, in which criminal records comprising all court convictions for infractions of the penal law are kept for all citizens until 2 years after their death. For those found in the CCR, we obtained information about the type of offence, the time of conviction, and the sentence applied. As this information was given in legal terms and paragraphs, it was categorised by an experienced jurist.

For statistical analyses, Fisher's exact test and the Wilcoxon rank sum test were used. The significance level was chosen as $5 \%$.

ETHICS

The study was based on register data only, and no subject was contacted personally. None of the subjects had undergone presymptomatic genetic testing. When analysing the data, only serial numbers were used, as all person identifiable information from the CCR was anonymised before given to the investigators. With these procedures, the study was approved by the Danish Ethics Committee System and carried out in accordance with the Declaration of Helsinki (II).

\section{Results}

As the rates of registered offences in all subgroups were found to be very different in men and women, results are reported separately for the two sexes:

MEN

Prevalence of crime

In the group of male patients $27(27.3 \%)$ were registered in the CCR (table 1) for one or more convictions. The median number of convictions was one (range 1-16) and the median age at first conviction was 36 years (range 18-69). Due to the insidious onset of the disease, reliable information concerning the age at onset is often difficult to obtain and was not available in all patients. We therefore were not able to distinguish rates of crime committed before and after onset of the disease. In the group of control subjects matched to the male 
Table 1 Registered offences in four groups of male subjects

\begin{tabular}{llllllll}
\hline & $\begin{array}{l}\text { Group } \\
n=99 \\
\%\end{array}$ & $\begin{array}{l}\text { Group } b \\
n=99 \\
\%\end{array}$ & $\begin{array}{l}\text { Groups } \\
\text { avb } \\
\text { pValue }\end{array}$ & $\begin{array}{l}\text { Groupc } \\
n=134 \\
\%\end{array}$ & $\begin{array}{l}\text { Groupd } \\
n=134 \\
\%\end{array}$ & $\begin{array}{l}\text { Groups } \\
\text { Tvd } \\
p \text { Value }\end{array}$ & $\begin{array}{l}\text { Groups } \\
\text { av c } \\
p \text { Value }\end{array}$ \\
\hline Traffic offences & 8.1 & 6.1 & NS & 3.0 & 0 & NS & NS \\
Drunken driving & 14.1 & 2.0 & 0.003 & 3.7 & 3.7 & NS & 0.006 \\
Violent crimes & 6.0 & 1.0 & NS & 1.5 & 0 & NS & NS \\
Theft & 9.1 & 7.1 & NS & 3.0 & 4.5 & NS & NS \\
Vandalism & 2.0 & 0 & NS & 0 & 0 & NS & NS \\
Fraud & 5.1 & 4.0 & NS & 0.7 & 0 & NS & NS \\
Other offences & 5.1 & 1.0 & NS & 1.5 & 0.7 & NS & NS \\
All types & 27.3 & 12.1 & 0.012 & 9.7 & 7.5 & NS & 0.001 \\
\hline
\end{tabular}

${ }^{\star}$ Figures are not additive, as several subjects were registered with more than one type of offence. Across group comparisons based on Fisher's exact test.

Groups: $a=$ patients with Huntington's disease; $b=$ control subjects matched to group $a$ $c=$ non-affected first degree relatives, about $9 \%$ are carriers of the gene for Huntington's disease (see text for details); $d=$ control subjects matched to group c.

patients, $12(12.1 \%)$ were registered as offenders, the median number of convictions being one (range 1-8) and the median age at first conviction 27.5 (range 20-73) years. The frequency of criminal offenders in the patients was significantly increased with a factor 2.3 compared with the control subjects $(p=0.012$, Fisher's exact test). For the 27 patients and the 12 control subjects, neither the distributions for age at first conviction nor the distributions for number of convictions showed significant differences (Wilcoxon rank sum test).

Among the non-affected first degree relatives of patients, $13(9.7 \%)$ were registered in the CCR (table 1). The median number of convictions was one (range 1-6) and the median age at first conviction 51 (range 24-70) years. In the matched control group, $10(7.5 \%)$ were registered in the CCR, the median number of convictions was one (range 1-2), and the median age at first conviction 57 (range 20-76) years. There was no significant difference between the distributions for the first degree relatives and the matched controls concerning number of convictions and age at first conviction.

When comparing the patients to the relatives, it should be remembered that patients as a group were younger than the group of relatives, therefore having fewer years available for criminal activity. Nevertheless, it was found that 2.8 times as many patients with Huntington's disease as first degree relatives of patients were registered in the CCR $(27.3 \% v 9.7 \%)$. This difference was highly significant $(\mathrm{p}=0.001$, Fisher's exact test). The median number of convictions was one in both distributions. For the relatives, however, the

Table 2 Registered offences in four groups of female subjects

\begin{tabular}{lllll}
\hline Type of offence & $\begin{array}{l}\text { Group } 1 \\
n=151 \\
\%\end{array}$ & $\begin{array}{l}\text { Group } 2 \\
n=151 \\
\%\end{array}$ & $\begin{array}{l}\text { Group } 3 \\
n=200 \\
\%\end{array}$ & $\begin{array}{l}\text { Group } 4 \\
n=200 \\
\%\end{array}$ \\
\hline Traffic offences & 1.3 & 0.7 & 0.5 & 0 \\
Drunken driving & 0.7 & 1.3 & 0 & 0 \\
Violent crimes & 0.7 & 0.7 & 0 & 0 \\
Theft & 2.0 & 3.3 & 1.0 & 0.5 \\
Vandalism & 0 & 0 & 0 & 0 \\
Fraud & 0.7 & 0 & 0 & 0 \\
Other offences & 0.7 & 0.7 & 0 & 0 \\
All types & 4.6 & 6.0 & 1.5 & 0.5
\end{tabular}

ॠFigures are not additive, as some subjects were registered with more than one type of offence. The numbers of offences in general were small, and no significant differences were found (Fisher's exact test).

Groups: 1=patients with Huntington's disease; $2=$ control subjects matched to group 1 ; $3=$ non-affected first degree relatives, about $9 \%$ are carriers of the gene for Huntington's disease (see text for details); $4=$ control subjects matched to group 3 . highest number of convictions was six, whereas four of the 27 criminal patients $(15 \%)$ had between seven and 16 convictions. The ages at first conviction were not comparable, as the first degree relatives were older than the patients due to the selection criteria. Among the first degree relatives as well as among the matched controls, there was a small group of subjects who had committed their first crime at a relatively old age (above 65 years). Due to their younger age, this was rarely found in patients and patient controls, explaining the lower median age at first crime in these two groups.

\section{Types of offences}

These were divided into seven categories, as shown in table 1. Because the importance of alcohol related problems in Huntington's disease has been debated, ${ }^{12}$ and as drunken driving occurred often in the sample, we listed this category separately. Traffic crimes without alcohol involvement typically were cases of reckless driving. The category of violent crimes included offences such as assault, molestation, and robbery, all involving the use or threat of physical violence. It should be noted that no cases of murder or rape were found in the sample. Theft included stealing other than robbery. The rest group of other offences was heterogenous and included a few cases of minor sexual offences, maltreatment of animals, illegal hunting, absence from military, and offences against drug law. It is seen that all types of offences were more frequent in the group of patients with Huntington's disease than in the control group. The frequency was significantly increased in the category of drunken driving, which was registered in $14.1 \%$ of the patients and only $2.0 \%$ of the controls (relative risk $=7.1, p=0.003$, Fisher's exact test). The patients also showed significantly higher rates of offences than first degree relatives in the category of drunken driving $(14.1 \%$ v $3.7 \%$, relative risk $=3.8, p=0.006$, Fisher's exact test). No differences were found between the groups of non-affected first degree relatives and controls.

WOMEN

Frequencies of offenders and types of registered offences are shown in table 2. Neither patients with Huntington's disease nor first degree relatives differed significantly from their respective control groups. More female patients than first degree relatives were registered with a criminal record, but the difference was not significant (Fisher's exact test). For types of offences, the numbers in each category were small, and no significant differences were found across groups. Median numbers of convictions in patients with offences was one (range 1-4), in matched controls one (range $1-4$ ), in first degree relatives one (range 1-2) and in the corresponding control group one (range 1-1). Median age at first conviction in patients was 36 (range 20-71) years, in controls 48 (range 31-69) years, among first degree relatives 55 (range 47-64) years, and in the matched control group 55 (range 55-55) 
years. No significant differences were found between the distributions for these two variables.

\section{Discussion}

In this investigation we have demonstrated:

(1) Increased risk of criminal convictions in male patients with Huntington's disease compared with controls and with first degree relatives.

(2) No increased risk in female patients.

(3) No increased risk in male and female first degree relatives.

All sorts of crime were overrepresented in male gene carriers, most marked and significant in the category of drunken driving, whereas the most serious offences such as arson, rape, or murder did not appear in the sample at all. The present data did not allow us to make the distinction whether crime was committed before or after onset of Huntington's disease. Our findings thus indicate increased prevalences of relatively less severe criminal behaviour among men, who are going to develop or who already have Huntington's disease.

It should be noted that only crime leading to convictions has been registered, whereas data on undetected crime do not exist. It might be that patients, due to dementia or other disturbances, were more likely to be arrested when acting illegally. If so, this could partly explain the raised conviction rates. We have no information on this matter, but we do not find it plausible that this could fully explain the marked differences showed here.

Recent studies indicate increased prevalences of criminal behaviour among patients with major mental disorders. Increased rates of violent criminality have been found in male as well as female schizophrenic patients. ${ }^{13}{ }^{14}$ In a register study of a Swedish birth cohort, ${ }^{15}$ both men and women with major mental disorders (schizophrenia, other psychoses, and major affective disorders) were at increased risk of crime in general and of violent crime. The largest study to date of crime and mental disorder seems to be the register study by Hodgins et al of a Danish birth cohort. ${ }^{16}$ When persons with a history of admission to a psychiatric ward were compared with controls, it was found that prevalences of all sorts of criminal convictions were increased in all psychiatric diagnostic categories. Specific mental disorders, including the group of organic mental disorders, therefore, were not associated with any specific category of crime. Although these findings were true for both sexes, crime rates in males were markedly higher than in females.

The association between crime and dementia has been reviewed by Jacoby, ${ }^{17}$ who concludes that even though increased offending might be expected in demented patients, due to the lack of inhibitions seen in many demential states, there is no scientific evidence supporting this expectation. Studies in this area are few and unsystematic; however, it seems likely that much aggressive and insulting behaviour in clearly demented patients lead to treatment of some kind, not to conviction.

Our findings imply that crime rates in men carrying the gene for Huntington's disease are increased to a level equal to what is seen in other groups of psychiatric patients. It seems reasonable to assume that criminal behaviour in these subjects often will be associated with the personality changes including irritability, impulsive behaviour, poor self control, and verbal as well as physical aggressiveness, often described as being early signs of the development of Huntington's disease. ${ }^{1}$

Highly increased rates of convictions of drunken driving indicate increased prevalences of problem drinking or even alcohol addiction among male patients. Alcoholism has been described as often occurring in Huntington's disease families, ${ }^{4}$ whereas other investigators found similar rates of alcoholism in patients with Huntington's disease and in the normal population. ${ }^{12}$ In our own study of psychiatric morbidity in Huntington's disease families, we did not find increased rates of diagnoses of alcoholism in patients in hospital compared with relatives and controls. ${ }^{5}$ The present results show that alcohol misuse may be a considerable problem in male carriers of the Huntington's disease gene, probably closely linked to the personality changes mentioned above, even though this problem does not in itself lead to admission to hospital. Also, the alcohol misuse might be secondary to depressive reactions after awareness of the development of the disease or difficulties from coping with the disablement. Major affective disorder thus has been found to be a common occurrence in patients of both sexes with Huntington's disease. $^{18}$

We did not find increased rates of convictions in women carrying the Huntington's disease gene, a finding contrasting with the studies of groups of other psychiatric patients, in whom crime rates were increased in both sexes compared with the normal population. The numbers of criminal offenders were small, however, in all groups of women, and definite conclusions are difficult to draw. Sex differences in the symptomatology of Huntington's disease have been described by Tamir et $a l^{19}$ who found males more likely to be aggressive and females to show depression. This confirms the generally recognised assumption, that lowered mood is often differently expressed in the two sexes, as males are more likely than females to present with acting out behaviour.

The design of the present study provided the possibility of direct comparison of two groups of offspring of patients with Huntington's disease; one group possessing the gene for Huntington's disease and having developed the disease themselves, and one group of nonaffected offspring, containing only about $9 \%$ of gene carriers. Both groups could be considered exposed to the same enduring and considerable stressors, being brought up in Huntington's disease families, as offspring of disabled parents, often aware of the marked risk of themselves developing the devastating disorder. Despite these stressors, non-affected first 
degree relatives were no more likely than controls to develop criminal behaviour, indicating that environmental factors in the families in itself did not lead to increased crime rates in offspring of patients.

In conclusion, our data indicate that criminal behaviour in Huntington's disease seems to be (1) increased in men only, (2) of low severity, and (3) related to the disease process, not to environmental and familial factors shared by patients and non-affected siblings. The mechanism behind increased crime rates in male gene carriers may be genetic, mediated through the personality changes often seen as the first discrete signs of onset of disease, but depressive reactions, leading to alcohol misuse and alcohol related traffic crimes, may also play a part.

We thank William Sørensen for help in categorising the types of offences. The study was supported by Illum Fondet and Fonden af 1982 .

1 Harper PS, ed. Huntington's disease. London: WB Saunders, 1996.

2 Huntington's Disease Collaborative Research Group. A novel gene containing a trinucleotide repeat that is expanded and unstable in Huntington's disease. Cell 1993; 72:971-83.

3 Hayden MR, Ehrlich R, Parker H, et al. Social perspectives in Huntington's chorea. S Afr Med f 1980;58:201-3.

4 Oliver JE. Huntington's chorea in Northamptonshire. $\mathrm{Br} f$ Psychiatry 1970;116:241-53. 5 Jensen P, Sørensen SA, Fenger K, et al. A study of psychiat-
ric morbidity in patients with Huntington's disease, their relatives and controls. Admissions to psychiatric hospitals in Denmark from 1969-91. Br F Psychiatry 1993;163:790-

6 Reed TE, Chandler JH. Huntington's chorea in Michigan. Am f Hum Genet 1958;10:201-25.

7 Parker N. Observations on Huntington's chorea based on a Queensland survey. Med F Aust 1958;45:351-9.

8 Dewhurst K, Oliver JE, McKnight AL. Socio-psychiatric consequences of Huntington's disease. Br $\mathcal{F}$ Psychiatry 1970;116:255-8.

9 Folstein SE, Franz ML, Jensen BA, et al. Conduct disorder and affective disorder among the offspring of patients with Huntington's disease. Psychol Med 1983;13:45-52.

10 Fenger K, Sørensen SA. A computerised register for HuntFenger K, Sørensen SA. A computerised register for Hu
ington's chorea in Denmark. Clin Genet 1986;29:460-1.

11 Harper PS, Newcombe RG. Age at onset and life table risks in genetic counselling for Huntington's disease. $\mathcal{F}$ Med

12 King M. Alcohol abuse in Huntington's disease. Psychol Med 1985;15:815-9.

13 Lindqvist P, Allebeck P. Schizophrenia and crime. A ongitudinal follow up of 644 schizophrenics in Stockholm. Br f Psychiatry 1990;157:345-50.

14 Wessely SC, Castle D, Douglas AJ, et al. The criminal careers of incident cases of schizophrenia. Psychol Med 1994;24:483-502

15 Hodgins S. Mental disorder, intellectual deficiency, and crime. Evidence from a birth cohort. Arch Gen Psychiatry 1992;49:476-83.

16 Hodgins S, Mednick SA, Brennan PA, et al. Mental disorder and crime. Evidence from a Danish birth cohort. Arch Gen Psychiatry 1996;53:489-96.

17 Jacoby R. Psychiatric aspects of crime and the elderly. In: Jacoby R, Oppenheimer C, eds. Psychiatry in the elderly. Oxford: Oxford University Press, 1997:749-60.

18 Folstein SE, Abbott MH, Chase GA, et al. The association of affective disorder with Huntington's disease in a case series and in families. Psychol Med 1983;13:537-42.

19 Tamir A, Whittier J, Korenys C. Huntington's chorea; a sex difference in psychopathological symptoms. Diseases of the Nervous System 1969;30:103. 